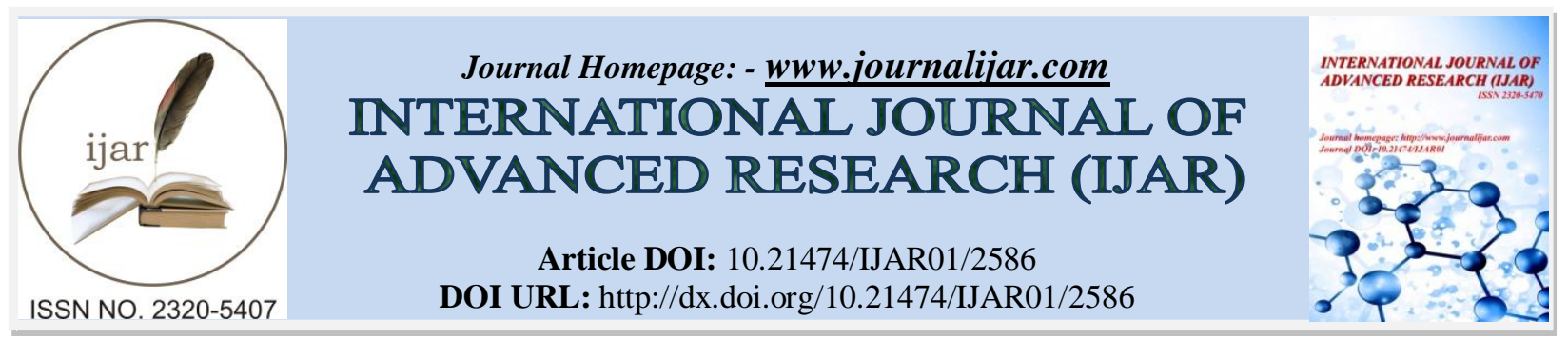

RESEARCH ARTICLE

\title{
ASSESSMENT OF KNOWLEDGE, ATTITUDE AND PRACTICE OF RED FLAGS RELATED TO ACUTE LOW BACK PAIN AMONG PRIMARY HEALTH CARE PHYSICIAN, MINISTRY OF HEALTH, JEDDAH 2013-2014.
}

\author{
Mohammed Ahmed Alghamdi, Ahmed Mansour Mattar and Omar Adnan Yamani. \\ Ministry of Health, Jeddah, Saudi Arabia.
}

\section{Manuscript Info} .

\section{Manuscript History}

Received: 27 October 2016

Final Accepted: 25 November 2016

Published: December 2016

Key words:-

Low back pain, knowledge, attitude, practice, red flags, primary care physicians

\section{Abstract}

Background: Low back pain is a very common condition, about $90 \%$ of people suffering from it at some point in their lives. It is a leading cause of lost time at work and disability. For example, in the USA, it is responsible for an annual direct health care expenditure of more than $\$ 20$ billion.

Objectives: To assess the level of knowledge, attitude and practice of primary health care physicians, Ministry of Health regarding red flags of acute low back pain in Jeddah in 2014.

Subjects and Methods: A cross-sectional study design among a representative random sample of physicians at PHC centers of Ministry of Health was adopted. Data were collected through selfadministrative questionnaire included socio-demographic data, knowledge data checklists about eleven red flags of acute low back pain: prolonged use of corticosteroids, age $>50$ years, significant trauma, bladder dysfunction, saddle anesthesia, fever with chills or night sweat, history of malignancy, lower extremities neurological deficit, weight loss, rest or night pain and immune suppression patients and the last partcontained 12 items that assessed the consistency of respondent agreement with the COST B13 guidelines.

Results: The study included 180 physicians. Approaching half of them $(46.6 \%)$ was in the age group 20-30 years. Females represent $60 \%$ of them. Most of them were Saudis (77.8\%). Previous education or training in relation back pain and red flags components was reported among more than half of them $(51.1 \%)$ during their undergraduation whereas during post-graduation was reported by $28.9 \%$. The first red flags of acute low back known by the primary health care physicians were Bladder dysfunction $(83.9 \%)$, age over 50 years (77.2\%), history of trauma $(73.3 \%)$ and weight $(68.9 \%)$ whereas the lowest known red flag of acute low back pain was pain less than two weeks $(8.3 \%)$. Consultants had high level of knowledge more than assistant consultants, residents and general practitioners. Physicians with none previous education or training in relation to back pain and red flags components had less level of knowledge than those reported under graduate, postgraduate and continuous medical education in this regard. The total average score was (3.27) with $\mathrm{SD} \pm$ (0.57).

Corresponding Author:- Mohammed Ahmed Alghamdi.

Address:- Family medicine specialist, Ministry of Health, Jeddah, Saudi Arabia. 
Conclusion: The knowledge of primary health care physicians in Jeddah regarding red flags of acute back pain is satisfactory in general. However, their attitude and practice of red flags of acute low back pain is suboptimal.

Copy Right, IJAR, 2016,. All rights reserved.

\section{Introduction:-}

Acute low back pain is one of the most common reasons for adults to see a family physician, about $90 \%$ of people suffering from it at some point in their lives. ${ }^{1}$ It is a leading cause of lost time at work and disability. For example, in the USA, it is responsible for an annual direct health care expenditure of more than $\$ 20$ billion. $^{2}$ Although most patients recover quickly with minimal treatment, proper evaluation is imperative to identify rare cases of serious underlying pathology. ${ }^{3}$

Low back pain is defined as pain and discomfort, localized below the costal margin and above the inferior gluteal folds, with or without leg pain.4

Acute low back pain is usually defined as the duration of an episode of low back pain persisting for less than 6 weeks. Sub-acute low back painisa low back pain persisting between 6 and 12 weeks. Chronic low back painisa low back pain persisting for 12 weeks or more. Recurrent low back pain is defined as a new episode after a symptomfree period of 6 months, but not an exacerbation of chronic low back pain. Nonspecific low back pain is defined as low back pain not attributed to recognizable, known specific pathology (e.g. infection, tumour, osteoporosis, ankylosing spondylitis, fracture, inflammatory process, radicular syndrome or caudaequina syndrome). ${ }^{4}$

The initial clinical history taking should aim at identifying 'red flags' of possible serious spinal pathology. ${ }^{5}$ 'Red flags' are risk factors detected in low back pain patients' past medical history and symptomatology and are associated with a higher risk of serious disorders causing low back pain compared to patients without these characteristics. If any of these are present, further investigation (according to the suspected underlying pathology) may be required to exclude a serious underlying condition, e.g. infection, inflammatory rheumatic disease or cancer. $^{5}$

Low back pain affects about $70 \%$ of people in resource-rich countries at some point in their lives. Acute low back pain can be self-limiting. Acute low back pain has a high recurrence rate; $75 \%$ of those with a first episode have a recurrence. Although acute episodes may resolve completely, they may increase in severity and duration over time. ${ }^{6}$

A cross-sectional study was conducted using sample of secondary schools teachers in Al-Khobar area, Saudi Arabia . Prevalence of musculoskeletal pain disorders was $79.17 \%$. Main sites of painwere lower back $(63.8 \%)^{7}$

Low back pain is currently the second most common cause of disability in the United States and is the most common cause of disability in those under age of $45 .{ }^{8}$ Back pain accounted for $40 \%$ of absences from work, second only to the common cold. ${ }^{9}$

This study aimed to assess the level of knowledge, attitude and practice of primary health care physicians, Ministry of Health regarding red flags of acute low back pain in Jeddah in 2014.

\section{Subjects and Methods:-}

This study is a cross- sectional analytical study carried out among a representative sample of Family physicians and general practitioners (GPs) working in the Ministry of Health (MOH) at Primary health care centers during the study period in Jeddah city. Jeddah is located in the middle of the eastern coast of the red sea known as the 'Bride of the Red Sea' and is considered the economic and tourism capital of the country. Its population is estimated around 3.4 million and it is the second largest city after Riyadh. ${ }^{\mathbf{4 7} 10}$

The total number of family physicians and general practitioners is 326 physicians (98 Family physician and 228 GPs) in 44 governmental (MOH) primary health care centers. ${ }^{4811}$ The sample size was calculated by Raosoft website for sample size calculation for proportion. It was 177 physicians; this is with a margin of error $5 \%, 95 \%$ confidence 
level and a reported prevalence rate of 50\% awareness of (5 out of 7) red flags items from the literature review of international studies. Centers were randomly selected by labeling each center with number starting from 1-44 and conduction of simple random sampling. Usually around 3-7 physicians are present in each PHC center. All physicians present in any selected center were included in the study during the period of conduction of the study. In average around 25 centers were included to fulfill our sample. The random sampling process of the centers was continued until we fulfilled the sample size keeping into consideration that each center was chosen once during the process of conducting this study.

A self-administered questionnaire, (the first and second parts) were designed by the researcher and they were tested in pilot study. Part 3 was adapted questionnaire from the COST B13 (European Cooperation in Science and Technology) guideline, it contained 12 items that assessed the consistency of respondent agreement with the COST B13 guidelines. The contents results from a consensus of experts (members of the COSTB13 group) testifying of its content validity. The internal consistency of the questionnaire has also been tested also it was tested in pilot study.

Written permissions from Joint Program of Family and Community Medicine and the higher authorities in the ministry of health to start the study after the approval by the local ethics committee were obtained before conducting the study. The individual consent from each physician to participate in the study is a prerequisite for data collection. A verbal consent was taken from each participant.

Data entry and analysis were done by using the Statistical Package of the Social Sciences statistical program (SPSS) version 20. Continuous variables were presented as means and standard deviation. Categorical variables were presented as frequencies and percentages. Student's t-test was applied for comparison of means of a continuous variables between two groups whereas ANOVA test was utilized to compare the means of continuous variables between more than two groups. Least significant difference test (LSD) was applied to compare between each two individual means in case of significant ANOVA test. P-value of less than 0.05 was considered as a level for significance throughout the study.

\section{Results:-}

The study included 180 physicians. Table 1 presents their demographic characteristics. Almost half of them (46.6\%) were in the age group 20-30 years whereas only 1.7\% of them were in the age group 51-60 years. Females represent $60 \%$ of them. Most of them were Saudis (77.8\%). More than half of them were general practitioners (52.8\%) and exactly one-third of them were residents. Consultants represent $6.7 \%$ of them. More than half of the physicians $(57.8 \%)$ practiced for more than 4 years whereas $18.9 \%$ practices for less than one year.

Previous education or training in relation back pain and red flags components was reported among more than half of them $(51.1 \%)$ during their under-graduation whereas during post-graduation was reported by $28.9 \%$. Training through CME was reported by $15.6 \%$ of them whereas only $4.4 \%$ were not trained

From figure 1, it is shown that the first red flags of acute low back known by the primary health care physicians were Bladder dysfunction (83.9\%), age over 50 years (77.2\%), history of trauma (73.3\%) and weight (68.9\%) whereas the lowest known red flag of acute low back pain was pain less than two weeks (8.3\%).

Table 2 shows the attitude and practice of primary health care physicians, Ministry of Health regarding red flags of acute low back pain. The total average score was (3.27) with standard deviation (0.57) which is in area of not sure.Come in first (Prescribe medication to relief pain help patient to recover normal daily activities) with arithmetic mean (4.11) and standard deviation (1.81) which present in area of not sure. While doctors do not agree on (A thorough history taking and physical examination are enough to exclude serious spinal diseases) with arithmetic mean (2.14) and standard deviation (2.28).

From table 3, it is seen that only physician`s title, experience and previous training were significantly associated with knowledge of red flags related to acute low back pain. Regarding physician`s title, to know the rate of differences, least significance difference test (LSD) has been made and showd that consultants had high level of knowledge more than assistant consultants, residents and general practitioners as well as resident had higher level of knowledge than general practitioners. Regarding physicians` experience, physicians who had an experience of more than 4 years had higher level of knowledge than those with one year or 1-4 years of experience. Regarding previous education or training in relation back pain and red flags components, physicians with none previous 
education or training in relation to back pain and red flags components had less level of knowledge than those reported under graduate, postgraduate and continuous medical education in this regard.

None of demographic characteristics of physicians was significantly associated with their attitude and practice of red flags of acute back pain as illustrated in table 4

Table 1:- Demographic characteristics of the physicians.

\begin{tabular}{|c|c|c|}
\hline & Frequency & Percentage \\
\hline Age & & \\
$20-30$ & 84 & 46.6 \\
$31-40$ & 70 & 38.9 \\
$41-50$ & 23 & 12.8 \\
$51-60$ & 3 & 1.7 \\
\hline Gender & 72 & 40.0 \\
Male & 108 & 60.0 \\
Female & 140 & 77.8 \\
\hline Nationality & 40 & 22.2 \\
Saudi & 12 & 6.7 \\
Non-Saudi & 13 & 7.2 \\
Title & 60 & 33.3 \\
Consultant & 95 & 52.8 \\
\hline Assistant consultant & & \\
Resident & 34 & 18.9 \\
General practitioner & 42 & 23.3 \\
\hline Years of practice & 104 & 57.8 \\
\hline 1 & &
\end{tabular}

Table 2:- Assessment of the attitude towards and practice of primary health care physicians regarding red flags of acute low back pain $(\mathrm{n}=180)$

\begin{tabular}{|c|c|c|c|c|}
\hline & & Mean & SD & Ranking \\
\hline 0 & $\begin{array}{l}\text { Prescribe medication to relief pain help patient to recover normal daily } \\
\text { activities }\end{array}$ & 4.11 & 1.81 & 1 \\
\hline 0 & Spine imaging abnormalities have a pathological meaning & 4.04 & 1.76 & 2 \\
\hline & $\begin{array}{l}\text { Spine is made to move. To take up activity early helps low back pain } \\
\text { patient to feel good }\end{array}$ & 3.78 & 1.82 & 3 \\
\hline 0 & Bed rest is recommended for low back pain management & 3.61 & 2.01 & 4 \\
\hline o & To stay active is a good way to cure low back pain & 3.61 & 1.90 & 5 \\
\hline 0 & $\mathrm{X}$-rays are not essential for low back pain diagnosis and management & 3.56 & 2.11 & 6 \\
\hline o & $\begin{array}{l}\text { Most of the acute low back pain are self limiting and have not important } \\
\text { consequence }\end{array}$ & 3.54 & 2.10 & 7 \\
\hline 0 & When it is prescribed, bed rest duration must be 2 days in minimum & 2.99 & 1.96 & 8 \\
\hline $\mathrm{O}$ & A severe low back pain means that severe spine lesions are present & 2.89 & 1.96 & 9 \\
\hline $\mathrm{o}$ & Spinal manipulation provided by professionals may worsen back pain & 2.66 & 1.61 & 10 \\
\hline $\mathrm{o}$ & Currently, low back pain does not reflect a serious disease & 2.32 & 2.08 & 11 \\
\hline & $\begin{array}{l}\text { A thorough history taking and physical examination are enough to exclude } \\
\text { serious spinal diseases }\end{array}$ & 2.14 & 2.28 & 12 \\
\hline \multicolumn{2}{|r|}{ Total } & 3.27 & 0.57 & \\
\hline
\end{tabular}


Table 3:- Association between knowledge of red flags of acute low back pain and demographic characteristics of primary health care physicians,

\begin{tabular}{|c|c|c|c|c|c|c|}
\hline \multicolumn{2}{|c|}{ Demographic characteristics } & Sum of & $\mathrm{df}$ & Mean & $\mathrm{F}$ & p-value \\
\hline \multirow[t]{3}{*}{ Age } & Between Groups & 7.698 & 3 & 2.566 & 0.498 & 0.684 \\
\hline & Within Groups & 906.947 & 176 & 5.153 & & \\
\hline & Total & 914.644 & 179 & & & \\
\hline \multirow{3}{*}{$\begin{array}{l}\text { Physician` } \\
\text { title }\end{array}$} & \multirow{3}{*}{$\begin{array}{l}\text { Between Groups } \\
\text { Within Groups } \\
\text { Total }\end{array}$} & 106.310 & 3 & 35.437 & 7.716 & $<0.001$ \\
\hline & & 808.334 & 176 & 4.593 & & \\
\hline & & 914.644 & 179 & & & \\
\hline \multirow{3}{*}{$\begin{array}{l}\text { Experience } \\
\text { (years) }\end{array}$} & \multirow{3}{*}{$\begin{array}{l}\text { Between Groups } \\
\text { Within Groups } \\
\text { Total }\end{array}$} & 106.310 & 3 & 35.437 & 7.716 & $<0.001$ \\
\hline & & 808.334 & 176 & 4.593 & & \\
\hline & & 914.644 & 179 & & & \\
\hline \multirow[t]{4}{*}{ Previous training } & \multirow{4}{*}{$\begin{array}{l}\text { Between Groups } \\
\text { Within Groups } \\
\text { Total } \\
\end{array}$} & 40.413 & 3 & 13.471 & 2.712 & 0.047 \\
\hline & & 874.231 & 176 & 4.967 & & \\
\hline & & 914.644 & 179 & & & \\
\hline & & $\mathrm{N}$ & \multicolumn{2}{|l|}{ Mean } & $\mathrm{t}$ & $p$-value \\
\hline \multirow[t]{2}{*}{ Sex } & Male & 72 & \multicolumn{2}{|l|}{7.1389} & -1.540 & 0.125 \\
\hline & Female & 108 & \multicolumn{2}{|l|}{7.6667} & & \\
\hline \multirow[t]{2}{*}{ Nationality } & Saudi & 140 & \multirow{2}{*}{\multicolumn{2}{|c|}{$\begin{array}{l}7.3929 \\
7.6750\end{array}$}} & -0.695 & 0.488 \\
\hline & Non-Saudi & 40 & & & & \\
\hline
\end{tabular}

Table 4:- Association between physicians` attitude and practice of red flags of acute back pain and demographic characteristics of primary health care physicians

\begin{tabular}{|c|c|c|c|c|c|c|}
\hline \multicolumn{2}{|c|}{ Demographic characteristics } & Sum of & $\mathrm{df}$ & Mean & $\mathrm{F}$ & p-value \\
\hline \multirow[t]{3}{*}{ Age } & Between Groups & 0.410 & 3 & .137 & 0.415 & 0.742 \\
\hline & Within Groups & 58.001 & 176 & .330 & & \\
\hline & Total & 58.411 & 179 & & & \\
\hline \multirow{3}{*}{$\begin{array}{l}\text { Physician` } \\
\text { title }\end{array}$} & \multirow{3}{*}{$\begin{array}{l}\text { Between Groups } \\
\text { Within Groups } \\
\text { Total }\end{array}$} & 1.921 & 3 & .640 & 1.995 & 0.116 \\
\hline & & 56.490 & 176 & .321 & & \\
\hline & & 58.411 & 179 & & & \\
\hline \multirow{3}{*}{$\begin{array}{l}\text { Experience } \\
\text { (years) }\end{array}$} & \multirow{3}{*}{$\begin{array}{l}\text { Between Groups } \\
\text { Within Groups } \\
\text { Total }\end{array}$} & .724 & 2 & .362 & 1.110 & .332 \\
\hline & & 57.687 & 177 & .326 & & \\
\hline & & 58.411 & 179 & & & \\
\hline \multirow[t]{4}{*}{ Previous training } & \multirow{4}{*}{$\begin{array}{l}\text { Between Groups } \\
\text { Within Groups } \\
\text { Total } \\
\end{array}$} & 2.187 & 3 & .729 & 2.282 & .081 \\
\hline & & 56.225 & 176 & .319 & & \\
\hline & & 58.411 & 179 & & & \\
\hline & & $\mathrm{N}$ & \multicolumn{2}{|l|}{ Mean } & $\mathrm{t}$ & $p$-value \\
\hline \multirow[t]{2}{*}{ Sex } & Male & 72 & \multicolumn{2}{|l|}{3.2674} & -0.093 & 0.926 \\
\hline & Female & 108 & \multicolumn{2}{|l|}{3.2755} & & \\
\hline \multirow[t]{2}{*}{ Nationality } & Saudi & 140 & \multirow{2}{*}{\multicolumn{2}{|c|}{$\begin{array}{l}3.2393 \\
3.3875\end{array}$}} & -1.452 & 0.148 \\
\hline & Non-Saudi & 40 & & 3.3875 & & \\
\hline
\end{tabular}




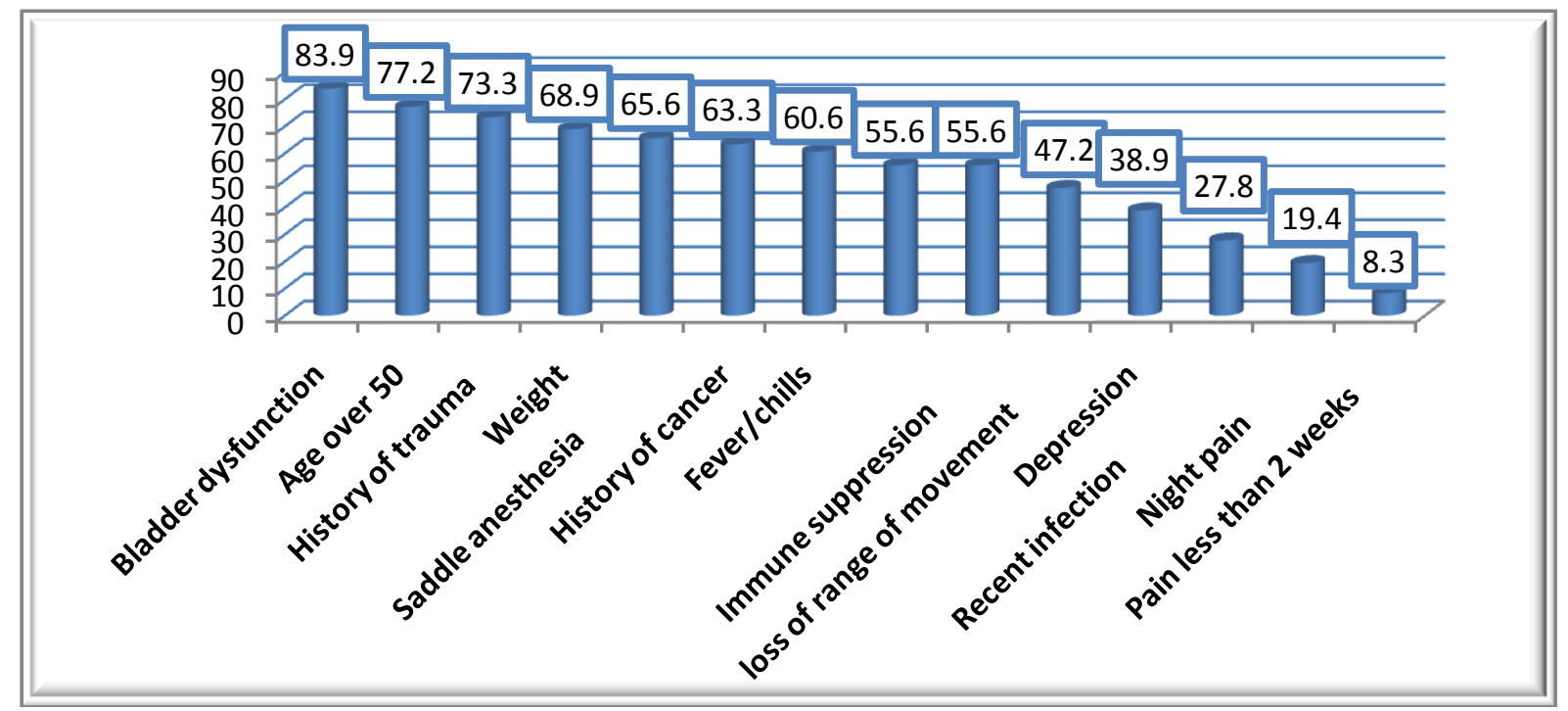

Figure 1:- Knowledge of primary health care physicians regarding red flags of acute low back pain.

\section{Discussion:-}

Limited knowledge is available, particularly in Saudi Arabia about the information delivered by physicians to patients with low back pain. Some studies have shown disagreement between the information provided by the physician and the expectations of patients with LBP. ${ }^{49-51}$ 12-14 Patient information regarding LBP is often based on physician's assumptions of what patients may want or need to know; yet physician's assumptions are often incomplete or incorrect in this regard. ${ }^{52,5315,16}$

The lack of accurate physician knowledge can have a negative impact on patient knowledge, despite the fact that patients express a need for a wide range of information on leisure activity, financial(social security for the treatment), psychological, social as well as clinical matters related to LBP. ${ }^{5417}$ Therefore, this study was conducted mainly to assess the level of knowledge, attitude and practice of primary health care physicians, Ministry of Health regarding red flags of acute low back pain.

The current results are consistent with previous published studies demonstrating that general practitioners had the lowest knowledge regarding red flags of acute LBP compared to consultants, senior registrar, registrar and even residents. ${ }^{49,5512,18}$

In the present study, the highest reported attitudes towards patients with acute LBP were prescribing medication to relief pain help patient to recover normal daily activities with arithmetic mean (4.1), spine imaging abnormalities have a pathological meaning with arithmetic mean (4.0), spine is made to move. To take up activity early helps low back pain patient to feel good with arithmetic mean (3.8), bed rest is recommended for low back pain management with arithmetic mean (3.6), and to stay active is a good way to cure low back pain with arithmetic mean (3.6). In a study conducted by Henrotin et al ${ }^{55}{ }^{18}$ using the same tool, the five commonest reported attitudes of physicians towards acute LBP were Prescribe medication to relief pain help patient to recover normal daily activities (5.0), Spine is made to move. To take up activity early helps low back pain patient to feel good (4.8), A severe low back pain does not mean that severe spine lesions are present (4.6), Bed rest is not recommended for low back pain management and to stay active is a good way to cure low back pain (4.5). The slightest higher score reported in their study could be attributed to the fact that they included GPs and rheumatologists while we have included only primary health care physicians. ${ }^{5518}$ They reported in their study that the attitude score was higher in rheumatologists than in GP that indicating that RH were more likely than GP to provide information congruent with the guidelines to their LBP patients. They explained that by the fact that more rheumatologists than GPs have participated in at least one course on LBP management and they reported reading more papers and attending more congresses on LBP than GPs. However, they reported that GP were better responders to information than rheumatologists as they had a lower baseline consistency score. In addition, they hold more fear-avoidance beliefs than rheumatologists. ${ }^{5518}$ 
The concordance of primary health care in the present study with the guidelines relating to the bed rest duration was poor. These results are consistent with previous published studies demonstrating that the provision of clinical practice guidelines is only partially successful in significantly improving physician concordance with the guideline. These guideline recommended treatment with diminished recommendations of prolonged bed rest and passivetherapies and an increase in recommended aerobic exercise. ${ }^{55,5618,19}$

These findings also indicate that guidelines regarding the management of patients' information have not been fully implemented into the patterns of practice of the physicians. In a study conducted by Henrotin et al, ${ }^{5518}$ even after delivery of the brochure summarizing the guidelines, the attitude score was on average, only $71 \%$. An appropriate next step is to devise more effective methods for implementing the guidelines. This could be accomplished, for example, via a media campaign targeting both physicians and patients, adapted to health-care system infrastructure and based on a consensus between evidence-based guidelines and patient's expectations. Previous studies have shown that education programmes or mass media campaigns could modify GP practice behaviours for LBP. ${ }^{.57,58} 20$, 21

Evidencealso indicates that promoting adherence to the LBPguidelines requires more than enhancing knowledge about evidence-based management of LBP. ${ }^{59}{ }^{22}$ Public education and an interdisciplinary consensus are important requirements for successful implementation of guidelines into daily practice.

Among important limitations of the present study, that hads to be mentioned, I tis based on self-reported medical practices. That is, there is no way to ensure that the findings reflect actual practice. Also, the findings were limited to one medical disciplines (PHC). Therefore, generalizability of results is questionable. The findings therefore need to be replicated in samples including physicians from other disciplines (e.g. orthopaedic surgeons, rheumatologists rehabilitators). Finally, the attitude questionnaire contained a limited number of items and may not have fully assessed all messages delivered by physicians during their consultation, although it was proved to be valid and reliable in a study carrier out by Henrotin et al. ${ }^{55} 18$

In conclusion, the knowledge of primary health care physicians in Jeddah regarding red flags of acute back pain is satisfactory in general. Majority them had previous education or training in relation back pain and red flags components. However, their attitude and practice of red flags of acute low back pain is suboptimal.

\section{References:-}

1. Frymoyer JW. Back pain and sciatica. The New England journal of medicine. 1988;318(5):291-300.

2. Deyo RA, Cherkin D, Conrad D, Volinn E. Cost, controversy, crisis: low back pain and the health of the public. Annual review of public health. 1991;12:141-56.

3. Casazza BA. Diagnosis and treatment of acute low back pain. American family physician. 2012;85(4):343-50.

4. van Tulder M, Becker A, Bekkering T, Breen A, del Real MT, Hutchinson A, et al. Chapter 3. European guidelines for the management of acute nonspecific low back pain in primary care. European spine journal : official publication of the European Spine Society, the European Spinal Deformity Society, and the European Section of the Cervical Spine Research Society. 2006;15 Suppl 2:S169-91.

5. Waddell G, Feder G, McIntosh A, Lewis M, Hutchinson A: Low Back Pain Evidence Review. London, England: Royal College of General Practitioners; 1996.

6. McIntosh G, Hall H. Low back pain (acute). Clin Evid (Online). 2011;2011.

7. Darwish MA, Al-Zuhair SZ. Musculoskeletal Pain Disorders among Secondary School Saudi Female Teachers. Pain research and treatment. 2013;2013:878570.

8. Centers for Disease Control and Prevention. Prevalence and most common causes of disability among adults United States, 2005. MMWR 2009;58:421-26.

9. Guo HR, Tanaka S, Halperin WE, Cameron LL. Back pain prevalence in US industry and estimates of lost workdays. American journal of public health. 1999;89(7):1029-35.

10. acute low back pain? The Journal of family practice. 2009;58(12):E1.

11. Kingdom of Saudi Arabia. Jeddah city. Available at: http://www.jeddah.gov.sa/english/JeddahCity/About.php

12. Ministry of Health, Saudi Arabia, Jeddah city. Available at: http://www.moh.gov.sa/Ministry/Statistics/Book/Pages/default.aspx

13. Cherkin D, Deyo RA, Berg AO, Bergman JJ, Lishner DM. Evaluation of a physician education intervention to improve primary care for low-back pain. I. Impact on physicians. Spine 1991; 16:1168-1172

14. Glenton C, Nilsen ES, Carlsen B. Lay perceptions of evidence-based information - a qualitative evaluation of a website for back pain sufferers. BMC Health Serv Res 2006; 6:34 
15. McIntosh A, Shaw CF. Barriers to patient information provision in primary care: patients' and general practitioners' experiences and expectations of information for low back pain. Health Expect 2003;6:19-29

16. Ostelo RW, Stomp-van den Berg SG, Vlaeyen JW, Wolters PM, de Vet HC. Health care provider's attitudes and beliefs towards chronic low back pain: the development of a questionnaire. Man Ther 2003;8:214-222

17. Jensen IB, Bodin L, Ljungqvist T, Gunnar Bergstrom K, Nygren A. Assessing the needs of patients in pain: a matter of opinion? Spine 2000;25:2816-2823

18. Gremeaux V, Coudeyre E, Givron P, Herisson C, Pelissier J, Poiraudeau S, et al. Qualitative evaluation of the expectations of low back pain patients with regard to information gained through semi-directed navigation on the Internet. Ann Readapt Med Phys 2007;50(348-55):339-347

19. Henrotin Y, Moyse D, Bazin T, Cedraschi C, Duplan B, Duquesnoy B. Study of the information delivery by general practitioners and rheumatologists to patients with acute low back pain. Eur Spine J 2011; 20:720-730

20. Bishop PB, Wing PC. Knowledge transfer in family physicians managing patients with acute low back pain: a prospective randomized control trial. Spine J 2006;6:282-288

21. Buchbinder R, Jolley D, Wyatt M. Volvo award winner in clinical studies: effects of a media campaign on back pain beliefs and its potential influence on management of low back pain in general practice. Spine 2001;26:2535-2542

22. Buchbinder R, Jolley D. Population based intervention to change back pain beliefs: three year follow up population survey. BMJ 2004;328:321

23. Chenot JF, Becker A, Leonhardt C, Keller S, Donner-Banzhoff N, Hildebrandt J, et al. Sex differences in presentation, course, and management of low back pain in primary care. Clin J Pain 2008;24:578-584 